\title{
Extension of Winding Function Theory for Modeling and Diagnosis of Partial Demagnetization Fault in PMSM Drive
}

\author{
Zakaria Gherabi ${ }^{1 *}$, Noureddine Benouzza' ${ }^{1}$ Azeddine Bendiabdellah¹, Djilali Toumi² \\ ${ }^{1}$ Diagnosis Group, LDEE Laboratory, Electrical Engineering Faculty, University of Sciences and Technology of Oran, Bir El Djir, \\ P. O. B. 1505, El-Mnaouar, Oran 31000, Algeria \\ 2 Electrical Engineering Department, L2GEGI Laboratory, Faculty of Applied Sciences, University of Ibn-Khaldoun of Tiaret, \\ P. O. B. P78, Tiaret 14000, Algeria \\ * Corresponding author, e-mail: zakaria.gherabi@univ-usto.dz
}

Received: 10 May 2020, Accepted: 08 July 2020, Published online: 14 June 2021

\begin{abstract}
This paper proposes the development of a new mathematical model dedicated to the diagnostic of the partial Demagnetization Fault (DF) in Permanent Magnet Synchronous Motor (PMSM). To do this, an extension of the Modified Winding Function Approach (MWFA) is proposed to accurately take into account the air gap asymmetry caused by the Demagnetization Fault (DF) in the PMSM inductances calculation. The calculated inductances are then used in the magnetically coupled electrical circuit model to simulate the PMSM behavior in the different operating modes. Finally, a diagnostic method based on the stator current spectral analysis is used to highlight the PMSM stator current spectral content in the various operating modes (with and without Demagnetization Fault).
\end{abstract}

\section{Keywords}

PMSM, MWFA, Demagnetization Fault (DF), stator current spectral analysis

\section{Introduction}

In recent decades, the use of PMSM is constantly increasing in many industrial and energy fields, such as rail and aeronautic transport, electric vehicles, electric traction, electric propulsion and wind farms. These motors, associated with inverters, have a more compact structure, a high specific power, and a higher dynamic response compared to conventional structures (direct current motors, synchronous wound rotor motors or induction motors) [1-8].

Unfortunately, during the PMSM operation several constraints of different natures can affect them. The accumulation of these constraints can cause failures in different parts of the PMSM. If these failures are not detected in time, they risk causing a progressive degradation of the motors. For this reason, it is important, from an industrial, economic, and scientific standpoint, to diagnose the faults affecting the PMSM as of their appearance. This early detection increases the life of these motors, thus minimizing financial losses due to the unscheduled shutdown of the production chain [1-3, 8].

Among these faults, the demagnetization of the Permanent Magnet (PM) is one of the most critical faults in PMSM, due to their relatively high cost which represents approximately $50 \%$ of the total cost of the machine $[3,9]$.
This type of fault can occur during abrupt load applications or in the presence of the short-circuit fault in the stator windings. Once produced, the irreversible reduction of PM remanent induction automatically reduces the overall performance of the PMSM system drive [10, 11].

In addition to the decrease of PM residual induction, it is known that some magnets such as Neodymium-IronBoron can deteriorate through disintegration. Fissures that form during manufacture can lead to disintegration at high speed. This disintegration leads to disruption of the air gap flux and the imbalance of the magnetic attraction between the rotor and the stator, which produces vibrations and stress on the PMSM bearings [12, 13].

PMSM modeling can be performed by different methods $[1,5,7,14,15]$. The most precise method consists in defining the real geometry of the PMSM studied. The Maxwell equations associated with the behavior laws of the materials used are then solved using numerical methods (Finite Elements Methods) [5, 7, 14]. Unfortunately, the major drawback of this method is the computation time, which can be quite long, especially for a finer mesh or a strong coupling between the different physical domains. 
Another method consists in modeling the PMSM by a complex network of permeance and associating to each elementary permeance the magnetic characteristic of the represented material [15]. This second method, a little less precise than the previous one and still requires too long computation time and the exact geometry knowledge of the machine.

In order to overcome the various drawbacks mentioned above, the winding function approach offers a good compromise in terms of model precision and calculation time. This approach is widely developed and used in literature [16-22]. It is an efficient method for analysis of electrical machines because it guarantees the consideration of the machine real geometry as well as the distribution of windings in the stator slots, which makes it possible to calculate the PMSM inductances taking into account all the space harmonics. According to [16], it was initially applied to highlight the performance of the constant air gap induction machine: it was first been tested on a single-phase motor in 1969 [17], a linear motor [18], a three-phase cage motor [19] and then a saturated motor [20]. It should be noted that this approach has also been applied to the analysis of other types of machines: the synchronous machine with salient poles [21, 22] and the direct current motor [23].

On the basis of this study, the presents paper proposes an extension of the MWFA, whose variation of the air gap permeance and the Permanent Magnet distribution function are used to calculate the different PMSM inductances in the presence of the Demagnetization Fault. This idea is inspired from a study which deals with the modeling of the salient pole synchronous machine taking into account the air gap non-uniformity [21].

In order to diagnose the DF in PMSM, many studies have been carried to analyze different types of measurable signals, [2, 3, 12, 24-27].

In papers [2,3], the most common methods that can be used to diagnose the DF in PMSM are discussed, summarized, and compared. In these papers, the fault indicators are classified according to the signal used in several types: current, voltage, torque, and magnetic flux indicators.

Moon et al. [26] proposed a method to diagnose the DF based on the monitoring of the PMSM inductances variation by using the recursive least square method. Unfortunately, this method requires a large computation time due to the complexity of their algorithms. According to Ebrahimi and Faiz [12], the DF fault increases the ripple of the electromagnetic torque of the PMSM with surface magnets and increases the amplitude of sideband components at particular frequencies in the electromagnetic torque spectrum. Furthermore, in [27], the authors presented the analysis of air gap flux density, measured by search coils installed around the stator teeth, as a diagnostic tool for the DF fault. A major disadvantage of this technique is the location of the magnetic flux sensors, which have to be placed inside the machine.

Note that, the stator current analysis is the most promising technique given the advantages it provides, namely $[1,6,8,28-31]$ :

- Using of a single current sensor instead of expensive and bulky equipment.

- Positioning of current sensors in any position from the supply voltage to the PMSM.

- Harmonic spectrum richness: The frequency location of certain harmonics provides us with important information about the PMSM condition and the different faulty types.

- Monitoring of the fault severity simple: This is possible by a simple monitoring of the magnitudes of their frequency signatures.

In this paper, the developing a new mathematical model of the PMSM in the presence of the partial DF is first developed. This model is based on an extension of the MWFA to calculate the different PMSM inductances taking into account the real PMSM geometry as well as the distribution of the windings in the stator slots. Then, the technique used to diagnose the DF is the one that uses the stator current as the quantity to be analyzed. Finally, to highlight the interest of the proposed model and the effectiveness of the technique used, a series of simulations will be presented.

\section{PMSM modeling}

The approach used to develop the PMSM behavioral model is based on the Magnetic Coupled Electrical Circuits (MCEC) approach. This approach is based on semi-analytical modeling of the PMSM using the electromagnetic coupling specific to its design and geometric topology.

MCEC approach has already proved its worth for stator fault modeling in induction motors [16-20] and PMSM $[1,6,8,32]$. It offers a good compromise in terms of the accuracy of the physical phenomena observed and the associated calculation time.

The PMSM model implementation using the MCEC approach requires two distinct development steps:

- The first step consists in establishing the different differential equations of the model;

- The second step consists in accurately determining the different inductances of the PMSM. 


\subsection{Permanent Magnet modeling}

In the classical model of the PMSM, the flux produced by the Permanent Magnets crossing the stator windings is modeled with low precision by a sinusoidal or trapezoidal magnetomotive force $[4,33]$.

To eliminate this simplification and develop a rich and flexible PMSM model, each Permanent Magnet located at the rotor will be modelled in this paper work by a virtual coil traversed by fictitious excitation currents as shown in Fig. 1.

This modeling makes it possible to change the Permanent Magnet topology and to perform a "virtual experiment" to simulate the PMSM behavior in the presence of the partial DF.

\subsection{PMSM equation system}

The electrical equations governing the PMSM operation are written in $[1,6,8,32]$ as

$\left[V_{s a b c}\right]=\left[R_{s}\right]\left[i_{s a b c}\right]+\frac{d}{d t}\left[\phi_{s a b c}\right]$

with

$$
\begin{aligned}
& {\left[V_{s a b c}\right]=\left[\begin{array}{c}
V_{s a} \\
V_{s b} \\
V_{s c}
\end{array}\right] ; \quad\left[i_{s a b c}\right]=\left[\begin{array}{c}
i_{s a} \\
i_{s b} \\
i_{s c}
\end{array}\right] ; \quad\left[\phi_{s a b c}\right]=\left[\begin{array}{c}
\phi_{s a} \\
\phi_{s b} \\
\phi_{s c}
\end{array}\right] ;} \\
& {\left[R_{s}\right]=\left[\begin{array}{ccc}
R_{s} & 0 & 0 \\
0 & R_{s} & 0 \\
0 & 0 & R_{s}
\end{array}\right]}
\end{aligned}
$$

$\left[V_{s a b c}\right]$ : Stator voltages vector;

$\left[i_{s a b c}\right]$ : Stator currents vector;

$\left[R_{s}\right]$ : Stator resistances matrix;

$\left[\phi_{s a b c}\right]$ : Stator fluxes vector.

Where the stator flux vector $\left[\phi_{s a b c}\right]$ is given by

$$
\left[\phi_{s a b c}\right]=\left[M_{s s}\right]\left[i_{s a b c}\right]+\left[M_{f}\right]\left[i_{f}\right]
$$

with

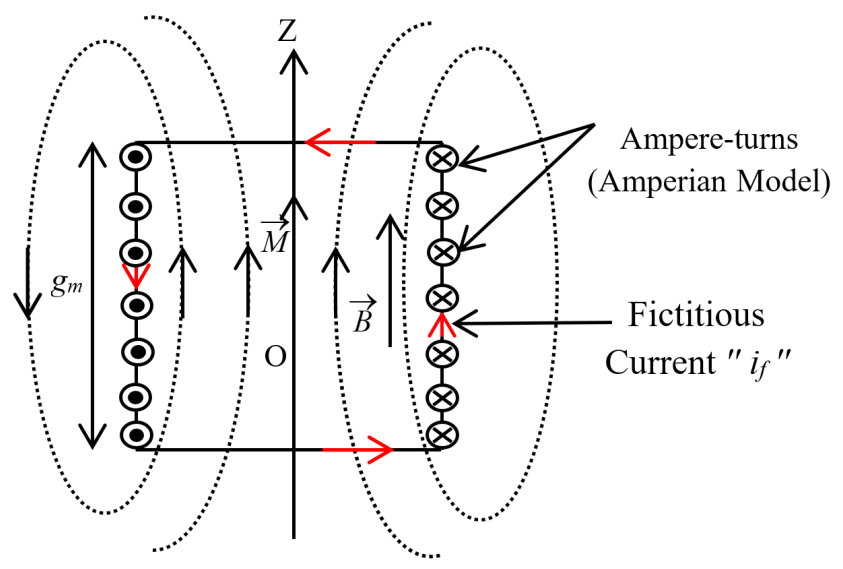

Fig. 1 Equivalent virtual coils for a Permanent Magnet

$$
\begin{aligned}
& {\left[M_{s s}\right]=\left[\begin{array}{ccc}
L_{s a a} & M_{s a b} & M_{s a c} \\
M_{s b a} & L_{s b b} & M_{s b c} \\
M_{s c a} & M_{s c b} & L_{s c c}
\end{array}\right] ; \quad\left[i_{f}\right]=\left[\begin{array}{c}
i_{f 1} \\
i_{f 2} \\
i_{f 3} \\
i_{f 4}
\end{array}\right] ;} \\
& {\left[M_{f}\right]=\left[\begin{array}{llll}
M_{s a f 1} & M_{s a f 2} & M_{s a f 3} & M_{s a f 4} \\
M_{s b f 1} & M_{s b f 2} & M_{s b f 3} & M_{s b f 4} \\
M_{s c f 1} & M_{s c f 2} & M_{s c f 3} & M_{s c f 4}
\end{array}\right]}
\end{aligned}
$$

$\left[M_{s s}\right]$ : Stator inductances matrix;

$\left[i_{f}\right]$ : Fictitious currents vectors;

$\left[M_{f}\right]$ : Stator/magnet mutual inductances matrix.

By replacing the Eq. (3) in Eq. (1), the relation obtained is

$$
\left[V_{s a b c}\right]=\left[R_{s}\right]\left[i_{s a b c}\right]+\frac{d\left\{\left[M_{s s}\right]\left[i_{s a b c}\right]\right\}}{d t}+\frac{d\left\{\left[M_{f}\right]\left[i_{f}\right]\right\}}{d t} .
$$

It is possible to obtain the voltage expression as a function of currents, flux and speed:

$\left[V_{s a b c}\right]=\left[R_{s}\right]\left[i_{s a b c}\right]+\left[M_{s s}\right] \frac{d\left[i_{s a b c}\right]}{d t}+\left[i_{f}\right] \frac{d\left[M_{f}\right]}{d t} \omega_{r}$.

The mechanical equation is written as follows:

$J \frac{d}{d t} \Omega+f \Omega=T_{e}-T_{l}$

\section{$J$ : Moment of inertia;}

$f$ : Coefficient of viscous friction;

$T_{e}$ : Electromagnetic torque;

$T_{l}$ : Load torque;

$\Omega$ : Mechanical speed.

Generally, the electromagnetic torque delivered by the PMSM; obtained from the Co-energy derivative ( $\partial W c o$ ) with respect to the electrical position of the rotor $\left(\theta_{r}\right)$; is given by Eq. (8):

$$
\begin{aligned}
& T_{e}=\frac{\partial W c o}{\partial \theta_{r}} \\
& =\frac{1}{2}\left[\left[i_{s a b c}\right]^{T} \frac{\partial\left[M_{s s}\right]}{\partial \theta_{r}}\left[i_{s a b c}\right]+2\left[i_{s a b c}\right]^{T} \frac{\partial\left[M_{f}\right]}{\partial \theta_{r}}\left[i_{f}\right]\right] .
\end{aligned}
$$

Given the matrix $\left[M_{s s}\right]$ which consists of a constant element, then the Eq. (8) becomes Eq. (9):

$$
T_{e}=\left[i_{s a b c}\right]^{T} \frac{\partial\left[M_{f}\right]}{\partial \theta_{r}}\left[i_{f}\right] \text {. }
$$

\section{Inductances calculation}

After the formalization of the PMSM model, the different inductances of the model must be determined with as much precision as possible in order to best translate the real physical phenomena of the PMSM in the different 
operating modes. To do this, a 2D extension of the MWFA is used. This approach of calculation is based on the use of the Eq. (10) to calculate the different inductances of the PMSM [19-22].

$$
L_{a b}=\mu_{o} r l \int_{o}^{2 \pi} N_{a}\left(\varphi, \theta_{r}\right) n_{b}\left(\varphi, \theta_{r}\right) g^{-1}\left(\varphi, \theta_{r}\right) \mathrm{d} \varphi
$$

Where $L_{a b}$ is the mutual inductance between windings $a$ and $b, \mu_{o}$ is the air permeability, $r$ is the mean radius of the gap, $l$ is the active length of the machine, $N_{a}\left(\varphi, \theta_{r}\right)$ is the winding function of the winding $a, n_{b}\left(\varphi, \theta_{r}\right)$ is the distribution function of the winding $b$, and $g^{-1}\left(\varphi, \theta_{r}\right)$ is the inverse of the gap function (see Fig. 2). With $\varphi$ is the position of the stator, and $\theta_{r}$ is the electrical rotor position.

\subsection{Inductance calculation in the healthy case}

To compute the different PMSM inductances in the healthy case, the air gap becomes uniform, so that the inverse of the air gap function $g^{-1}\left(\varphi, \theta_{r}\right)$ must be constant and equal to nominal air gap value $g_{o}$, which therefore allows the Eq. (10) to be rewritten as follows:

$L_{a b}=\frac{\mu_{o} r l}{g_{o}} \int_{o}^{2 \pi} N_{a}\left(\varphi, \theta_{r}\right) n_{b}\left(\varphi, \theta_{r}\right) \mathrm{d} \varphi$.

\subsubsection{Magnetization inductances of stator phases}

The magnetization inductances of the stator phases are calculated using the integral:

$L_{s a a}=\frac{\mu_{o} r l}{g_{o}} \int_{o}^{2 \pi} N_{a}\left(\varphi, \theta_{r}\right) n_{a}\left(\varphi, \theta_{r}\right) \mathrm{d} \varphi$.

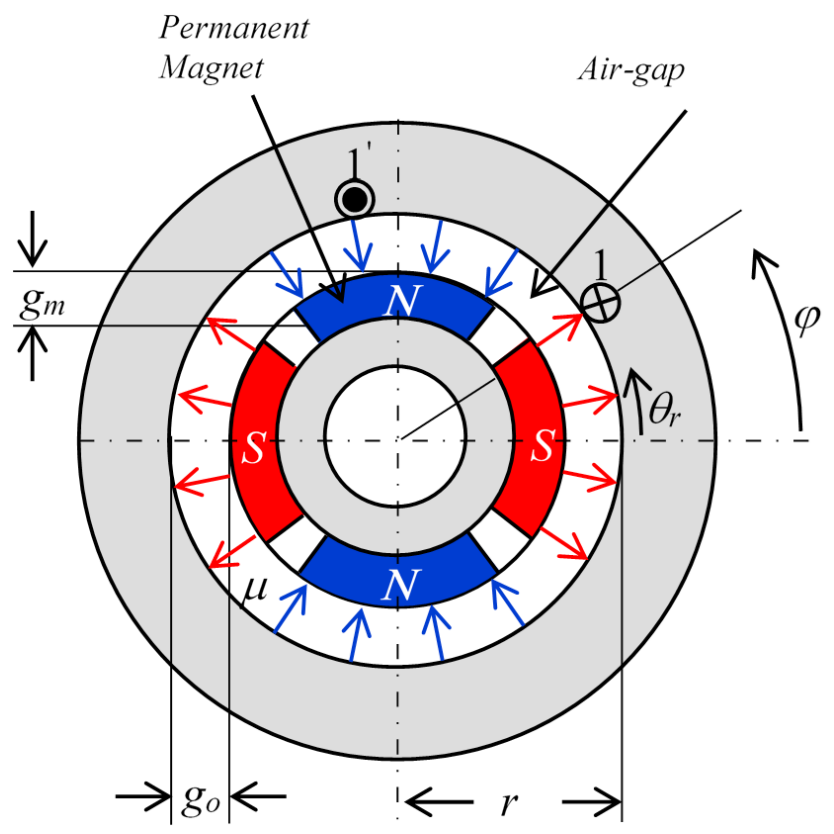

Fig. 2 Cross section of 4 pole PMSM
After calculation, these inductances are given as follows:

$L_{s a a}=\frac{\mu_{o} r l N_{s} N_{s}}{g_{o}} 220 \alpha_{s}$, with $L_{s a a}=L_{s b b}=L_{s c c}$.

\subsubsection{Mutual inductance between stator phases}

The mutual inductance between stator phases $a$ and $b$ is obtained as

$M_{s a b}=\frac{\mu_{o} r l}{g_{o}} \int_{o}^{2 \pi} N_{a}\left(\varphi, \theta_{r}\right) n_{b}\left(\varphi, \theta_{r}\right) \mathrm{d} \varphi$.

After calculation, it is found that

$M_{s a b}=-\frac{\mu_{o} r l N_{s} N_{s}}{g_{o}} 104 \alpha_{s}$ with $M_{s a b}=M_{s a c}=M_{s b c}$.

\subsubsection{Stator/magnet mutual inductances}

The mutual inductance $\left(M_{s a f 1}\right)$ between phase $a$ and the fictitious coil $f_{1}$ is obtained using the following integral:

$$
M_{s a f 1}=\frac{\mu_{o} r l}{g_{o}} \int_{o}^{2 \pi} N_{a}\left(\varphi, \theta_{r}\right) n_{f 1}\left(\varphi, \theta_{r}\right) \mathrm{d} \varphi .
$$

The expression of this inductance is obtained as a function of the relative position of the fictitious coil with respect to the windings of phase $a$. For every given interval, a value of the mutual inductance $M_{\text {saf } 1}$ is given as a function of $\left(\theta_{r}\right)$ (see Table 1). Where $\alpha_{s}=\pi / 18$ and $\alpha_{r}$ represents the magnet opening.

The mutual inductances between this fictitious coil and the other phases $b$ and $c$ will be deduced by the same method but shifted respectively by $\pi / 3$ and $2 \pi / 3$.

\subsection{Inductance calculation in the presence of the DF}

To compute the PMSM inductances in the presence of the DF fault, this paper work proposes an extension of the MWFA, whose variation of the air gap permeance and the Permanent Magnet distribution function are used to calculate these inductances.

All inductances are calculated in the same way as in the healthy case, but the inverse function of the air gap is not constant and the fictitious coil distribution function changes according to the partial DF degree $\delta_{d m}$.

In the presence of the partial DF, the inverse of the gap function depends on the thickness of the gap, the thickness of the part in fault, the degree and position of the DF. However, the distribution function of the faulty magnet depends on the location and degree of the Demagnetization Fault $\delta_{d m}$. Fig. 3 (a), Fig. 3 (b) and Fig. 3 (c) respectively illustrate the PMSM air gap variation, the inverse of the air gap function $g^{-1}\left(\varphi, \theta_{r}\right)$ and the distribution function 
Table 1 Variation of $M_{s a f 1}$ as function of $\theta_{r}$

\begin{tabular}{|c|c|}
\hline Inductance $M_{s a f 1}(\mathrm{H})$ & $\left(\theta_{r}\right)(\mathrm{rad})$ \\
\hline$\frac{\mu_{o} \times r \times l \times N_{s} \times N_{r}}{g_{o}}\left(5 \theta_{r}+3 \alpha_{r}-12 \alpha_{s}\right)$ & $0 \leq \theta_{r} \leq \alpha_{s}$ \\
\hline$\frac{\mu_{o} \times r \times l \times N_{s} \times N_{r}}{g_{o}}\left(4 \theta_{r}+3 \alpha_{r}-11 \alpha_{s}\right)$ & $\alpha_{s} \leq \theta_{r} \leq 2 \alpha_{s}$ \\
\hline$\frac{\mu_{o} \times r \times l \times N_{s} \times N_{r}}{g_{o}}\left(2 \theta_{r}+3 \alpha_{r}-7 \alpha_{s}\right)$ & $2 \alpha_{s} \leq \theta_{r} \leq 9 \alpha_{s}-\alpha_{r}$ \\
\hline$\frac{\mu_{o} \times r \times l \times N_{s} \times N_{r}}{g_{o}}\left(\theta_{r}+2 \alpha_{r}+2 \alpha_{s}\right)$ & $9 \alpha_{s}-\alpha_{r} \leq \theta_{r} \leq 3 \alpha_{s}$ \\
\hline$\frac{\mu_{o} \times r \times l \times N_{s} \times N_{r}}{g_{o}}\left(2 \alpha_{r}+5 \alpha_{s}\right)$ & $3 \alpha_{s} \leq \theta_{r} \leq 10 \alpha_{s}-\alpha_{r}$ \\
\hline$\frac{\mu_{o} \times r \times l \times N_{s} \times N_{r}}{g_{o}}\left(-\theta_{r}+\alpha_{r}+15 \alpha_{s}\right)$ & $10 \alpha_{s}-\alpha_{r} \leq \theta_{r} \leq 4 \alpha_{s}$ \\
\hline$\frac{\mu_{o} \times r \times l \times N_{s} \times N_{r}}{g_{o}}\left(-2 \theta_{r}+\alpha_{r}+19 \alpha_{s}\right)$ & $4 \alpha_{s} \leq \theta_{r} \leq 11 \alpha_{s}-\alpha_{r}$ \\
\hline$\frac{\mu_{o} \times r \times l \times N_{s} \times N_{r}}{g_{o}}\left(-4 \theta_{r}-\alpha_{r}+41 \alpha_{s}\right)$ & $11 \alpha_{s}-\alpha_{r} \leq \theta_{r} \leq 12 \alpha_{s}-\alpha_{r}$ \\
\hline$\frac{\mu_{o} \times r \times l \times N_{s} \times N_{r}}{g_{o}}\left(-5 \theta_{r}-2 \alpha_{r}+53 \alpha_{s}\right)$ & $12 \alpha_{s}-\alpha_{r} \leq \theta_{r} \leq 13 \alpha_{s}-\alpha_{r}$ \\
\hline$\frac{\mu_{o} \times r \times l \times N_{s} \times N_{r}}{g_{o}}\left(-6 \theta_{r}-3 \alpha_{r}+66 \alpha_{s}\right)$ & $13 \alpha_{s}-\alpha_{r} \leq \theta_{r} \leq 9 \alpha_{s}$ \\
\hline
\end{tabular}

\begin{tabular}{|c|c|c|}
\hline & Stator cylinder head & (a) \\
\hline$\left.g_{t}\right\rceil g_{o}$ & & $g_{m}$ \\
\hline$\downarrow \uparrow g_{f}$ & $N$ & $V$ \\
\hline \multicolumn{3}{|c|}{ Rotor cylinder head } \\
\hline
\end{tabular}
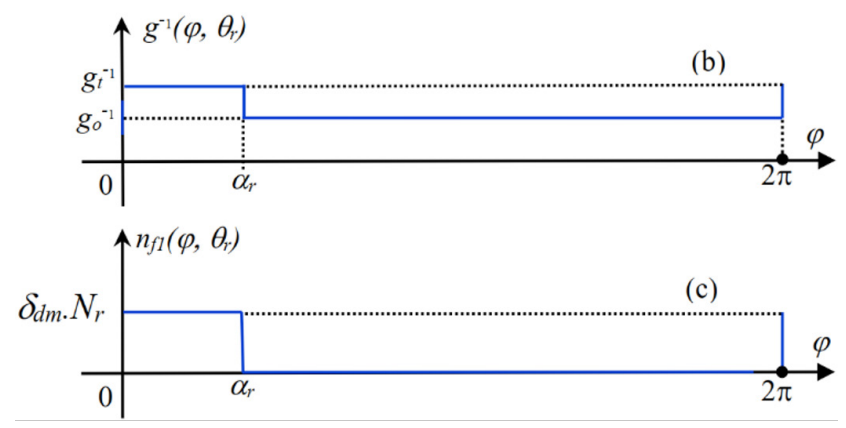

Fig. 3 (a) PMSM air gap variation, (b) inverse of the air gap function variation, (c) distribution function of the first fictitious coil $f_{1}$ variation in the presence of the partial DF in the first magnet

of the first fictitious coil $n_{f 1}\left(\varphi, \theta_{r}\right)$, in the case of partial demagnetization in the first magnet.

The variation of the inverse of the air gap function can be expressed as follows: $g^{-1}\left(\varphi, \theta_{r}\right)= \begin{cases}g_{t}^{-1} & 0 \leq \varphi \leq \alpha_{r} \\ g_{o}^{-1} & \text { at the remaining interval }\end{cases}$

with $g_{t}^{-1}=g_{o}^{-1}+g_{f}^{-1}$

$$
g_{f}^{-1}=\delta_{d m} g_{m}^{-1} \text { and } 0 \leq \delta_{d m} \leq 1 .
$$

Where $g_{o}$ is the air gap nominal thickness, $g_{m}$ is the Permanent Magnet thickness, $g_{f}$ is the faulty part thickness, $g_{t}$ is the total air gap thickness, $\delta_{d m}$ is the DF degree and $N_{r}$ is the fiction coil turns number.

\section{Stator current spectral content with and without DF}

The stator current analysis in the frequency domain remains the most commonly used method because the resulting spectrum contains a source of information on the majority of electrical and mechanical faults that can occur in the PMSM [1-3, 6, 8, 12, 34, 35].

\subsection{Healthy case}

In PMSM, the stator currents spectral content includes, in addition to the fundamental, a set of harmonics at the frequencies given by the Eq. (18). These harmonics are due to the switching of the inverter IGBTs and to the real distribution of the windings in the stator slots $[1-3,6,8]$.

$f_{s h}=(2 k+1) f_{s}$

\subsection{Cases with Demagnetization Faults}

These studies [2, 3] show that the DF is manifested by a signature on the spectrum of the stator current at the frequencies given by the Eq. (19). With $f_{s}$ the supply frequency, $P$ the pole pairs and $k$ a positive integer.

$$
f_{\mathrm{DF}}=\left(1+\frac{k}{p}\right) f_{s}
$$

\section{Simulation results}

Once the PMSM model has been established, the next step of the work is the simulation of this model in the following operating modes:

- Healthy Motor Operation Mode;

- Faulty Motor Operation Mode: presence of the DF.

The simulation program of this model is developed under the MATLAB environment. The parameters of the PMSM, the arrangement of the stator and rotor windings, as well as the diagram of the developed program are presented respectively in Appendices A, B, and C. 
The simulation parameters are as follows:

- The integration step: $h=10^{-4} \mathrm{~s}$;

- The simulation time: $T_{s}=5 \mathrm{~s}$;

- The sampling frequency: $F_{e}=1 / h=10 \mathrm{kHz}$;

- The frequency resolution $f=1 / T_{s}=0.2 \mathrm{~Hz}$.

In all simulations the PMSM is fed by a two-level inverter controlled by the MLI-SVM strategy with a switching frequency of $6 \mathrm{kHz}$.

\subsection{Healthy motor operation mode}

Fig. 4 and Fig. 5 show the electromechanical characteristics of the healthy motor under the nominal load $(17.5 \mathrm{Nm})$. Fig. 4 shows the plot of the supply voltage applied across phase $a$ of the PMSM.

Fig. 5 (a) depicts the PMSM rotational speed. If it is zoomed at the time $0.8 \mathrm{~s}$, it is then noticed the existence of fluctuations of $\pm 20 \mathrm{rpm}$ around to the PMSM theoretical speed $(2000 \mathrm{rpm})$. These fluctuations are caused by the real distribution of the MMF along the air gap and by the switching of the inverter IGBTs, which are translated in frequency domain by a series of harmonics at the frequencies given by the Eq. (18).

Fig. 5 (b) shows the waveforms of the three stator currents absorbed by the simulated motor. These currents are balanced at constant magnitudes in time. On the other hand, these currents are no more sinusoidal, they present fluctuations, which are due to the effect of space harmonics and to the inverter IGBTs switching.

Fig. 5 (c) shows the stator current spectrum of phase $a$. It contains in addition to the fundamental, a series of harmonics at frequencies given by the Eq. (18), which represents space and time harmonics. This analysis is considered as the reference for the next operating mode.

Theoretically, the DF signatures appear around the fundamental frequency. In the case of our PMSM all the parameters are fixed, which gives us the values of the different frequencies listed in Table 2.

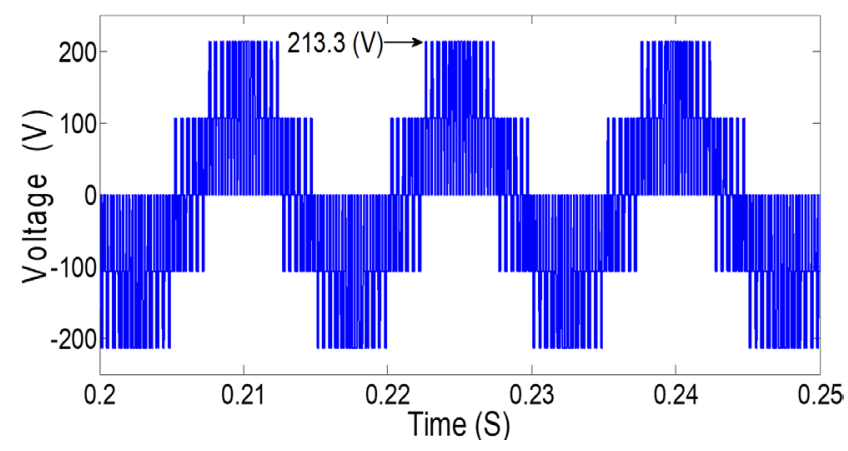

Fig. 4 Supply voltage applied to phase $a$ of the PMSM (a)

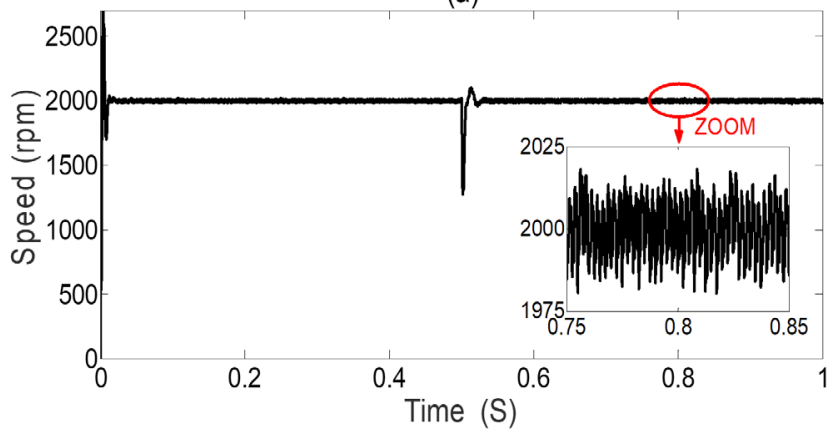

(b)

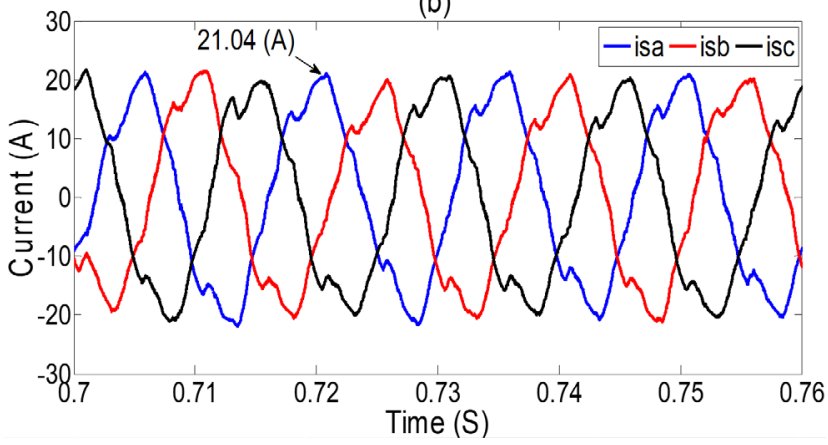

(c)

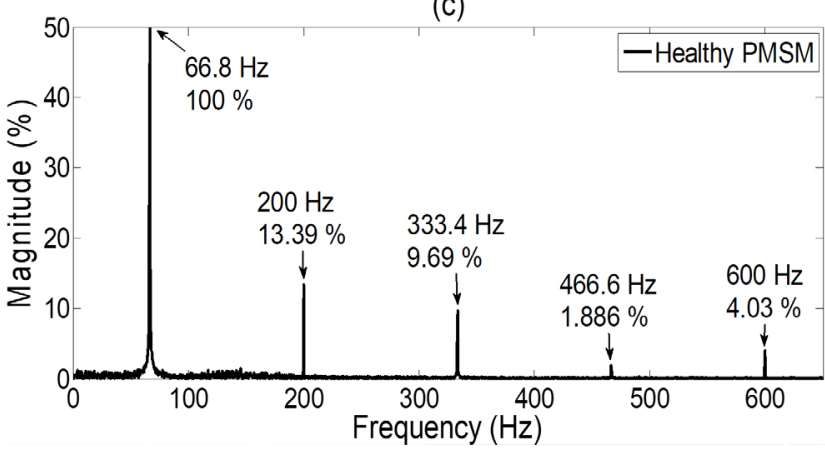

Fig. 5 (a) Rotational Speed, (b) Three stator currents, (c) Current spectrum of the phase $a$. - Healthy motor operation mode

Table 2 DF Theoretical Frequency signatures $(k=1)$

\begin{tabular}{lc}
\hline Frequency Signatures & Demagnetization Fault \\
\hline$f_{\mathrm{DF}}=(1-1 / P) f_{s}$ & $33.3 \mathrm{~Hz}$ \\
$f_{\mathrm{DF}}=(1+1 / P) f_{s}$ & $100 \mathrm{~Hz}$ \\
\hline
\end{tabular}

For a best reading of the spectrum, the analysis must focus particularly on these two frequencies (see Fig. 6).

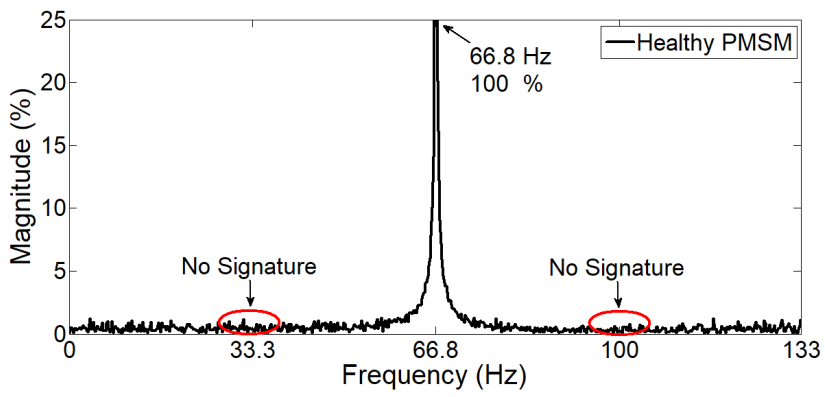

Fig. 6 Current spectrum of the phase $a$. - Healthy motor operation mode 


\subsection{Faulty motor operation mode with DF}

To simulate the operation of the PMSM in the presence of the partial Demagnetization Fault, the degree of DF $\left(\delta_{d m} \neq 0\right)$ of Eq. (17) is varied. The magnetizing inductance of phase $a$ and the mutual inductances between stator phases $a$ and $b$ are calculated for a demagnetization of $20 \%$ in the first magnet and shown in Fig. 7.

From Fig. 7 (a) and Fig. 7 (b) and using the Eq. (17), it can be noticed that these inductances become constant when the degree of demagnetization is zero (see Fig. 7 in red) and varying according to the air gap function variation when the degree of demagnetization is different to zero (see Fig. 7 in blue). Fig. 8 (a) and Fig. 8 (b) respectively show the variations of the mutual inductances between phase $a$ and the four fictitious coils $f_{1}, f_{2}, f_{3}$ and $f_{4}$ as well as their derivatives as a function of the rotor position for a DF of $20 \%$. According to Fig. 8 (a) and Fig. 8 (b), it can be noticed the decrease in the amplitude of the mutual inductance between phase $a$ and the first fictitious coil (the coil that represents the faulty magnet) compared to the other inductances (see Fig. 8 in blue).

Fig. 9 (a) illustrates the PMSM rotational speed. If it is zoomed at the time $0.8 \mathrm{~s}$, it is then noticed the increase in rotational speed ripples from $\pm 20 \mathrm{rpm}$ for a zero DF degree to $\pm 150 \mathrm{rpm}$ for a DF degree equal to $10 \%$.
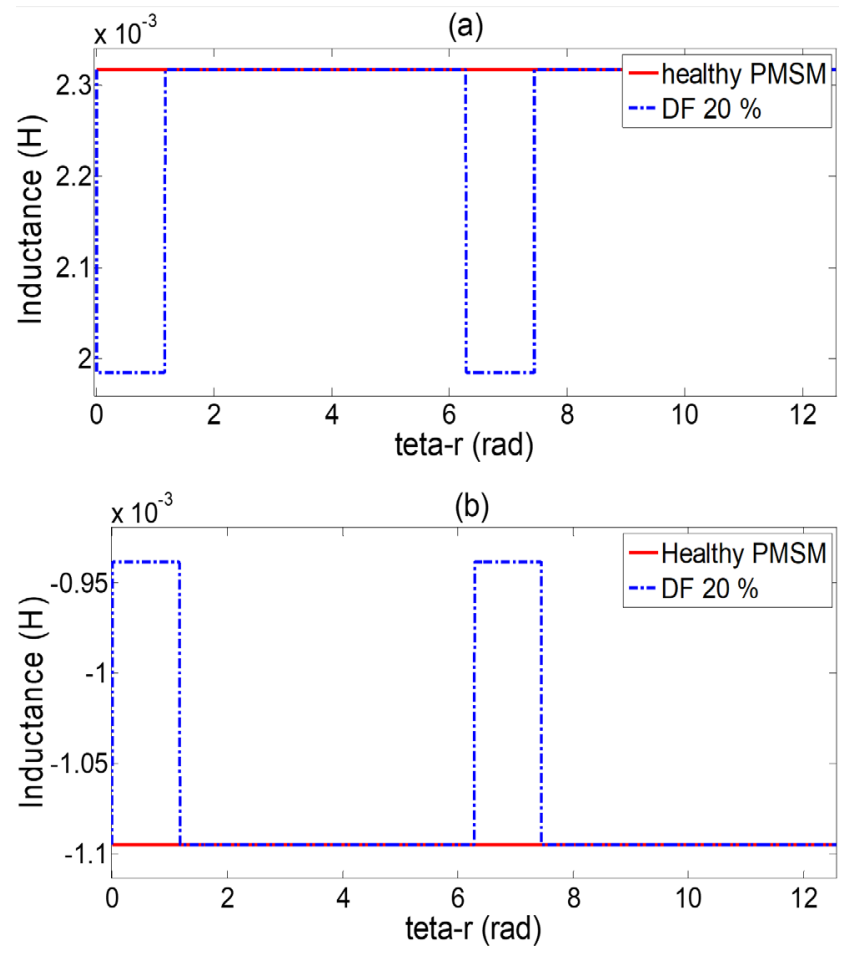

Fig. 7 (a) magnetization inductance of phase $a$, (b) mutual inductance between stator phases ( $a$ and $b$ ), for a DF of $20 \%$
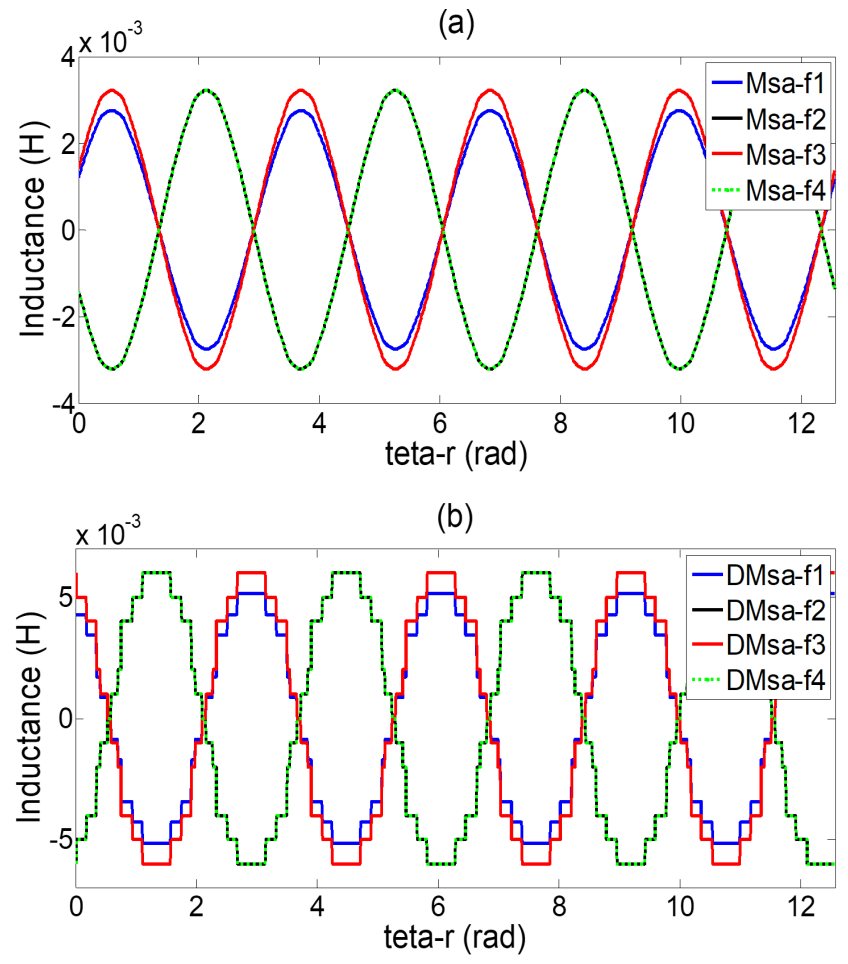

Fig. 8 (a) Mutual inductance between phase $a$ and the four fictitious coils $\left(f_{1}, f_{2}, f_{3}\right.$ and $\left.f_{4}\right)$, for a DF of $20 \%$, (b) Their derivatives

In addition, Fig. 9 (b) illustrates the three stator currents of the PMSM for a nominal load and a demagnetization of $10 \%$ in the first fictitious coil. It is noticed that there is a difference compared to the results obtained in the healthy case. The currents are not balanced and have different magnitudes and higher than those obtained in the healthy case (see Fig. 5 (b)).

Finally, the spectral analysis of the stator current of phase $a$ shows that the partial DF is manifested by the creation of a series of harmonics at frequencies given by the Eq. (19) (see Fig. 9 (c)). In addition, from Fig 10 and Table 3. It is noticed that the increase of the partial DF severity increases the magnitude of these harmonics' characteristics.

\section{Conclusion}

In this paper, a mathematical model dedicated to diagnose the partial Demagnetization Fault diagnosis in PMSM is proposed. This model; based on an extension of the MWFA to accurately take into account the air gap asymmetry caused by the DF; calculates precisely the different inductances of the PMSM.

The simulation results showed that the partial DF is manifested by the creation of a series of harmonics at fixed frequencies (depending on constant parameters such as: 
(a)

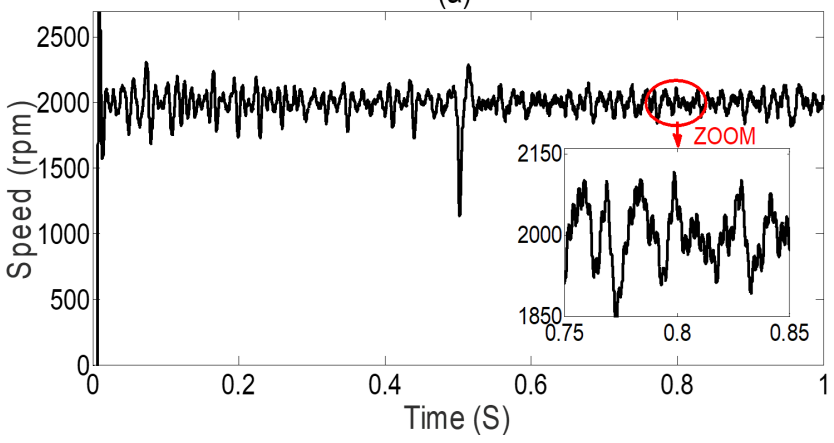

(b)

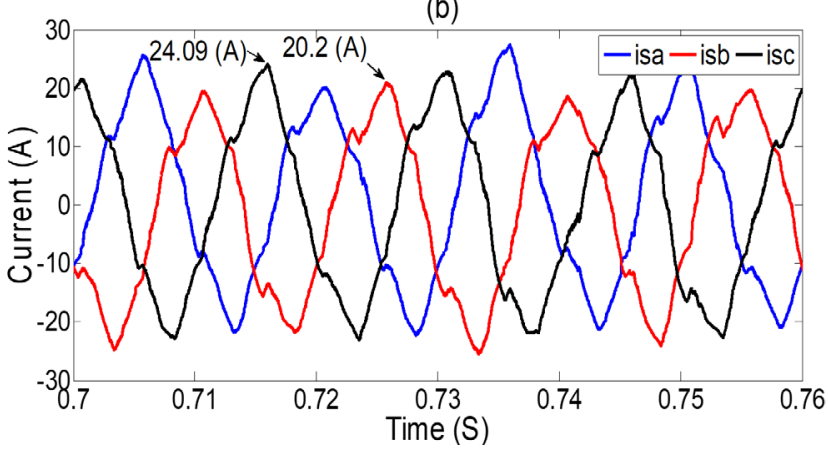

(c)

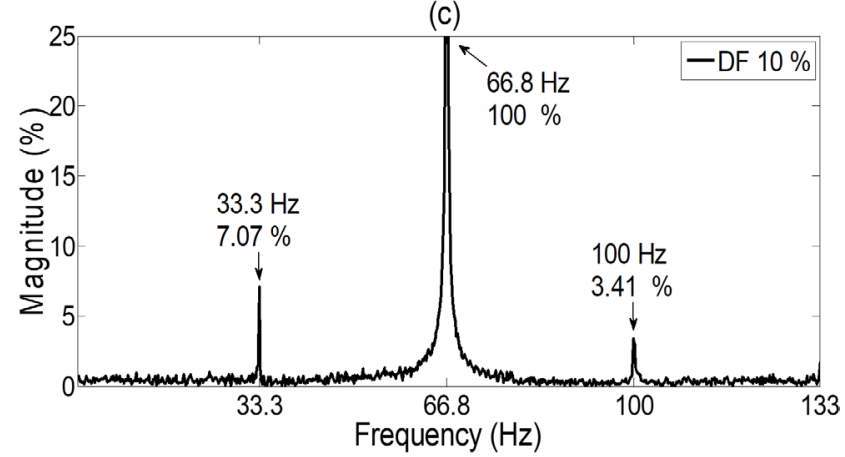

Fig. 9 Operation with partial DF (a) Speed of rotation, (b) Currents of three stator phases, (c) Current spectrum of phase $a$

\section{References}

[1] Gherabi, Z., Toumi, D., Benouzza, N., Denai, M. "Stator Inter-Turn Short-Circuit and Eccentricity Faults Detection in Permanents Magnets Synchronous Motors Using Line Current Spectrum Analysis", International Review of Electrical Engineering (IREE), 15(1), pp. 54-68, 2020.

https://doi.org/10.15866/iree.v15i1.17638

[2] Faiz, J., Nejadi-Koti, H. "Demagnetization Fault Indexes in Permanent Magnet Synchronous Motors-An Overview", IEEE Transactions on Magnetics, 52(4), pp. 1-11, 2016. https://doi.org/10.1109/TMAG.2015.2480379

[3] Maanani, Y., Menacer, A. "Modeling and Diagnosis of the Inter-Turn Short Circuit Fault for the Sensorless Input-Output Linearization Control of the PMSM", Periodica Polytechnica Electrical Engineering and Computer Science, 63(3), pp. 159-168, 2019. https://doi.org/10.3311/PPee.13658

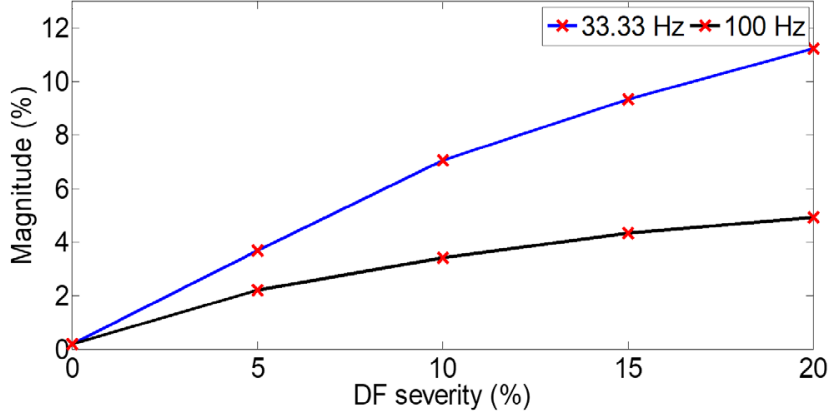

Fig. 10 Variation of the amplitudes of the partial DF characteristic harmonics as a function of the variation of its severity

Table 3 Variation of the amplitudes of the partial DF characteristic harmonics as a function of the variation of its severity

\begin{tabular}{lcccc}
\hline $\begin{array}{l}\text { DF severity } \\
(\%)\end{array}$ & 0 & 10 & 15 & 20 \\
\hline $\begin{array}{l}\text { Frequency } \\
(\mathrm{Hz})\end{array}$ & $\begin{array}{c}\text { Magnitude } \\
(\%)\end{array}$ & $\begin{array}{c}\text { Magnitude } \\
(\%)\end{array}$ & $\begin{array}{c}\text { Magnitude } \\
(\%)\end{array}$ & $\begin{array}{c}\text { Magnitude } \\
(\%)\end{array}$ \\
\hline 33.3 & 0.2 & 7.07 & 9.34 & 11.23 \\
100 & 0.18 & 3.41 & 4.33 & 4.94 \\
\hline
\end{tabular}

power frequency and number of pole pairs). In addition, the increase of the fault severity is manifested by the increase of the magnitude of these harmonics.

In the light of the results obtained, it is possible to confirm the effectiveness of the proposed model and the reliability of the stator current analysis technique for the Demagnetization Fault diagnosis.

[4] M'hamed, L., Zakaria, G., Khireddine, D. "A Robust Sensorless Control of PMSM Based on Sliding Mode Observer and Model Reference Adaptive System", International Journal of Power Electronics and Drive Systems (IJPEDS), 8(3), pp. 1016-1025, 2017. https://doi.org/10.11591/ijpeds.v8.i3.pp1016-1025

[5] Melecio, J. I., Djurović, S., Schofield, N. "FEA model study of spectral signature patterns of PM demagnetization faults in synchronous PM machines", The Journal of Engineering, 2019(17), pp. 4127-4132, 2019.

https://doi.org/10.1049/joe.2018.8048

[6] Gherabi, Z., Toumi, D., Benouzza, N., Henini, N. "Modeling and Diagnosis of Stator Winding Faults in PMSM using Motor Current Signature Analysis", In: International Aegean Conference on Electrical Machines Power Electronics (ACEMP), International Conference on Optimization of Electrical Electronic Equipment (OPTIM), Istanbul, Turkey, 2019, pp. 227-232.

https://doi.org/10.1109/ACEMP-OPTIM44294.2019.9007162 
[7] Gómez, I., Almandoz, G., Ugalde, G., Poza, J., Escalada, A. J. "Methodology to study demagnetization risk in permanent magnet machines by Finite Element Method", In: IEEE Workshop on Electrical Machines Design, Control and Diagnosis (WEMDCD), Nottingham, UK, 2017, pp. 262-267.

https://doi.org/10.1109/WEMDCD.2017.7947757

[8] Gherabi, Z., Benouzza, N., Toumi, D., Bendiabdellah, A. "Eccentricity Fault diagnosis in PMSM using Motor Current Signature Analysis", In: International Aegean Conference on Electrical Machines Power Electronics (ACEMP), International Conference on Optimization of Electrical Electronic Equipment (OPTIM), Istanbul, Turkey, 2019, pp. 205-210.

https://doi.org/10.1109/ACEMP-OPTIM44294.2019.9007164

[9] Ginzarly, R., Hoblos, G., Moubayed, N. "Faults in hybrid electric vehicles' permanent magnet machines", In: Third International Conference on Technological Advances in Electrical, Electronics and Computer Engineering (TAEECE), Beirut, Lebanon, 2015, pp. 169-174.

https://doi.org/10.1109/TAEECE.2015.7113621

[10] Fitouri, M., Bensalem, Y., Abdelkrim, M. N. "Effects of Design Variables on Demagnetization Fault in Permanent Magnet Synchronous Motor", In: 15th International Multi-Conference on Systems, Signals \& Devices (SSD), Yasmine Hammamet, Tunisia, 2018, pp. 71-76.

https://doi.org/10.1109/SSD.2018.8570605

[11] Gherabi, Z., Toumi, D., Benouzza, N., Boudinar, A. H., Koura, M. B. "Discrimination between demagnetization and eccentricity faults in PMSMs using real and imaginary components of stator current spectral analysis", In: Journal of Power Electronics, 21(1), pp. 153-163, 2021.

https://oi.org/10.1007/s43236-020-00169-6

[12] Ebrahimi, B. M., Faiz, J. "Demagnetization Fault Diagnosis in Surface Mounted Permanent Magnet Synchronous Motors", IEEE Transactions on Magnetics, 49(3), pp. 1185-1192, 2013. https://doi.org/10.1109/TMAG.2012.2217978

[13] Wang, C., Prieto, M. D., Romeral, L., Chen, Z., Blaabjerg, F., Liu, X. "Detection of Partial Demagnetization Fault in PMSMs Operating Under Nonstationary Conditions", IEEE Transactions on Magnetics, 52(7), pp. 1-4, 2016.

https://doi.org/10.1109/TMAG.2015.2511003

[14] Zhu, S., Cheng, M., Hua, W., Cai, X., Tong, M. "Finite Element Analysis of Flux-Switching PM Machine Considering Oversaturation and Irreversible Demagnetization", IEEE Transactions on Magnetics, 51(11), pp. 1-4, 2015.

https://doi.org/10.1109/TMAG.2015.2445774

[15] Gherabi, Z., Toumi, D., Benouzza, N., Becheikh, M. "Line Current Spectrum Analysis as a Technique to Diagnose the Demagnetization Fault in Permanent Magnet Synchronous Motor", In: Bououden, S., Chadli, M., Ziani, S., Zelinka, I. (eds.) Proceedings of the 4th International Conference on Electrical Engineering and Control Applications, Springer, Singapore, Singapore, 2019, pp. 915-930.

https://doi.org/10.1007/978-981-15-6403-1_63

[16] Faiz, J., Tabatabaei, I. "Extension of winding function theory for nonuniform air gap in electric machinery", IEEE Transactions on Magnetics, 38(6), pp. 3654-3657, 2002.

https://doi.org/10.1109/TMAG.2002.804805
[17] Davis, J. H., Novotny, D. W. "Equivalent Circuits for Single-Phase Squirrel-Cage Induction Machines with both Odd and Even Order MMF Harmonics", IEEE Transactions on Power Apparatus and Systems, PAS-88(7), pp. 1080-1086, 1969. https://doi.org/10.1109/TPAS.1969.292508

[18] Lipa, T. A., Nondahl, T. A. "Pole-by-Pole d-q Model of a Linear Induction Machine", IEEE Transactions on Power Apparatus and Systems, PAS-98(2), pp. 629-642, 1979. https://doi.org/10.1109/TPAS.1979.319448

[19] Toliyat, H. A., Lipo, T. A., White, J. C. "Analysis of a concentrated winding induction machine for adjustable speed drive applications. I. Motor analysis", IEEE Transactions on Energy Conversion, 6(4), pp. 679-683, 1991. https://doi.org/10.1109/60.103641

[20] Moreira, J. C., Lipo, T. A. "Modeling of saturated AC machines including air gap flux harmonic components", IEEE Transactions on Industry Applications, 28(2), pp. 343-349, 1992.

https://doi.org/10.1109/28.126740

[21] Faiz, J., Ebrahimi, B. M., Valavi, M., Toliyat, H. A. "Mixed Eccentricity Fault Diagnosis in Salient-Pole Synchronous Generator Using Modified Winding Function Method", Progress In Electromagnetics Research B, 11, pp. 155-172, 2009. https://doi.org/10.2528/PIERB08110903

[22] Toliyat, H. A., Al-Nuaim, N. A. "Simulation and detection of dynamic air-gap eccentricity in salient-pole synchronous machines", IEEE Transactions on Industry Applications, 35(1), pp. 86-93, 1999. https://doi.org/10.1109/28.740849

[23] Hajiaghajani, M., Toliyat, H. A., Panahi, I. M. S. "Advanced fault diagnosis of a DC motor", IEEE Transactions on Energy Conversion, 19(1), pp. 60-65, 2004. https://doi.org/10.1109/TEC.2003.819101

[24] Vinson, G., Combacau, M., Prado, T., Ribot, P. "Permanent magnets synchronous machines faults detection and identification", In: 38th Annual Conference on IEEE Industrial Electronics Society, Montreal, QC, Canada, 2012, pp. 3925-3930. https://doi.org/10.1109/IECON.2012.6389265

[25] Espinosa, A. G., Rosero, J. A., Cusidó, J., Romeral, L., Ortega, J. A. "Fault Detection by Means of Hilbert-Huang Transform of the Stator Current in a PMSM With Demagnetization", IEEE Transactions on Energy Conversion, 25(2), pp. 312-318, 2010. https://doi.org/10.1109/TEC.2009.2037922

[26] Moon, S., Lee, J., Jeong, H., Kim, S. W. "Demagnetization Fault Diagnosis of a PMSM Based on Structure Analysis of Motor Inductance", IEEE Transactions on Industrial Electronics, 63(6), pp. 3795-3803, 2016. https://doi.org/10.1109/TIE.2016.2530046

[27] Da, Y., Krishnamurthy, M. "Novel fault diagnostic technique for permanent Magnet Synchronous Machines using electromagnetic signature analysis", In: IEEE Vehicle Power and Propulsion Conference, Lille, France, 2010, pp. 1-6. https://doi.org/10.1109/VPPC.2010.5729130

[28] Harir, M., Bendiabdellah, A., Boudinar, A. H. "A Proposed Technique for Discrimination between Saturation Phenomenon and Short-Circuit Faults in Induction Motor", International Review on Modelling and Simulations (IREMOS), 11(5), pp. 333-342, 2018. https://doi.org/10.15866/iremos.v11i5.15465 
[29] Gherabi, Z., Toumi, D., Benouzza, N., Bendiabdellah A. "A Proposed Approach for Separation between Short Circuit Fault, Magnetic Saturation Phenomenon and Supply Unbalance in Permanent Magnet Synchronous Motor", International Journal of Engineering (IJE): Transactions A: Basics, 33(10), pp. 1968-1977, 2020. https://doi.org/10.5829/ije.2020.33.10a.15

[30] Benouzza, N., Boudinar, A. H., Bendiabdellah, A. "Slot harmonic frequency detection as a technique to improve stator current spectrum approach for eccentricity fault diagnosis", In: 6th International Conference on Control Engineering and Information Technology (CEIT), Istanbul, Turkey, 2018, pp. 1-6. https://doi.org/10.1109/CEIT.2018.8751941

[31] Bendiabdellah, A., Boudinar, A. H., Benouzza, N., Khodja M. "The enhancements of broken bar fault detection in induction motors", In: Intl Aegean Conference on Electrical Machines Power Electronics (ACEMP), Intl Conference on Optimization of Electrical and Electronic Equipment (OPTIM), Int1 Symposium on Advanced Electromechanical Motion Systems (ELECTROMOTION), Side, Turkey, 2015, pp. 81-86. https://doi.org/10.1109/OPTIM.2015.7426972
[32] Abdallah, A. A., Regnier, J., Faucher, J., Dagues, B. "Simulation of Internal Faults in Permanent Magnet Synchronous Machines", In: International Conference on Power Electronics and Drives Systems, Kuala Lumpur, Malaysia, 2005, pp. 1390-1395. https://doi.org/10.1109/PEDS.2005.1619906

[33] Pillay, P., Krishnan, R. "Modeling, simulation, and analysis of permanent-magnet motor drives. I. The permanent-magnet synchronous motor drive", IEEE Transactions on Industry Applications, 25(2), pp. 265-273, 1989.

https://doi.org/10.1109/28.25541

[34] Urresty, J.-C., Riba, J.-R., Romeral, L. "A Back-emf Based Method to Detect Magnet Failures in PMSMs", IEEE Transactions on Magnetics, 49(1), pp. 591-598, 2013. https://doi.org/10.1109/TMAG.2012.2207731

[35] Liu, Z., Huang, J., He, S. "Diagnosis of air-gap eccentricity and partial demagnetization of an interior permanent magnet synchronous motor based on inverse transient complex inductance vector theory", IET Electric Power Applications, 12(8), pp. 1166-1175, 2018. https://doi.org/10.1049/iet-epa.2018.0003

\section{Appendix A}

Table 4 PMSM Parameters

\begin{tabular}{|c|c|c|c|}
\hline Symbol & Description & Values & Units \\
\hline$V_{n}$ & Rated voltage & 260 & $\mathrm{~V}$ \\
\hline$f_{s}$ & Rated frequency & 66.7 & $\mathrm{~Hz}$ \\
\hline$I_{n}$ & Rated current & 15.1 & A \\
\hline$C_{n}$ & Rated torque & 17.5 & $\mathrm{Nm}$ \\
\hline$\Omega_{n}$ & Rated speed & 2000 & $\mathrm{rpm}$ \\
\hline$R_{s}$ & Stator resistance & 0.295 & $\Omega$ \\
\hline$L_{s}$ & Synchronous inductance & 3.5 & $\mathrm{mH}$ \\
\hline$J$ & Moment of inertia & $3.10-4$ & $\mathrm{Kg} \mathrm{m}^{2}$ \\
\hline$F$ & Viscous rubbing & 0.017 & $\mathrm{Nm} / \mathrm{rad} / \mathrm{s}$ \\
\hline$P$ & Pole Pairs Number & 2 & ---- \\
\hline$g_{o}$ & Nominal air gap & 12 & $\mathrm{~mm}$ \\
\hline$r$ & Stator radius & 64 & $\mathrm{~mm}$ \\
\hline$r r$ & Rotor radius & 52 & $\mathrm{~mm}$ \\
\hline$l$ & Length of the machine & 250 & $\mathrm{~mm}$ \\
\hline$N_{s}$ & Number of turns/Coil & 6 & ---- \\
\hline$\alpha_{r}$ & Magnet Opening & 1.15 & $\mathrm{rad}$ \\
\hline$g_{m}$ & Thickness of magnets & 10 & $\mathrm{~mm}$ \\
\hline
\end{tabular}




\section{Appendix B}

Fig. 11 (a) represents $n_{a}(\varphi)$ the distribution function of phase $a$ with a mean value $\left\langle n_{a}(\varphi)\right\rangle=3 \mathrm{Ns}$. This value allows us to find the winding function as shown in Fig. 11 (b). The phases $b$ and $c$ have the same form of distribution and winding functions but shifted respectively and lagging by $\pi / 3$ and $2 \pi / 3$. Fig. 11 (c) represents the distribution function of the fictitious coil $f_{1}$. The fictitious coils $f_{2}, f_{3}, f_{4}$ have the same form of distribution functions but shifted by an angle $k$. $\pi / 2$ respectively, with $k=1,2,3$.
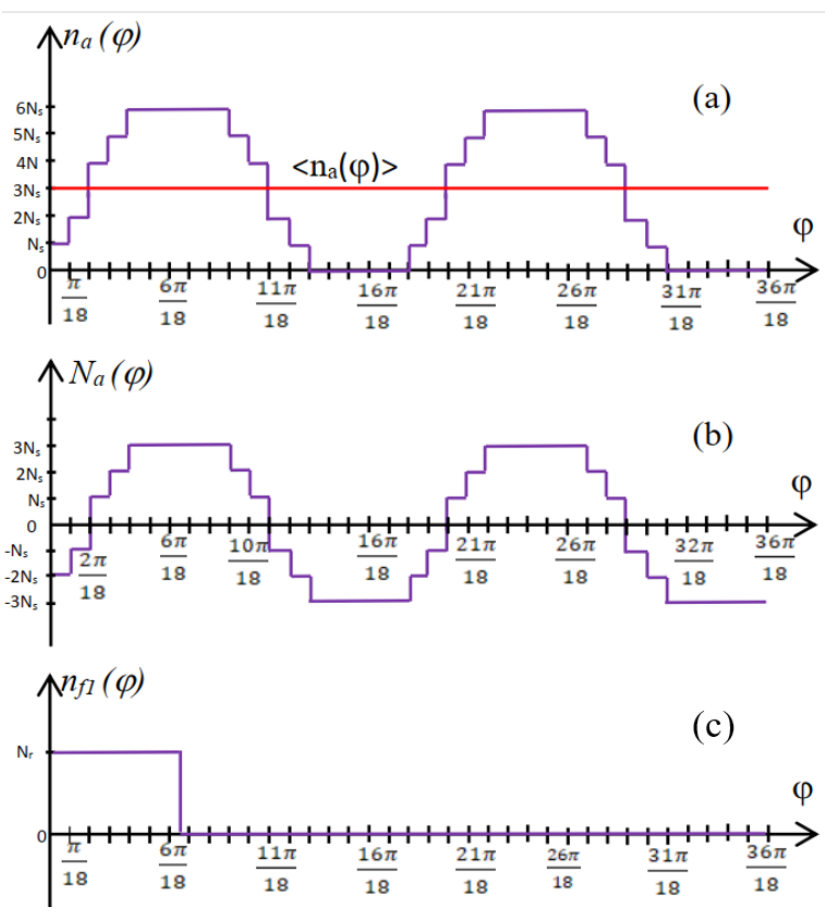

Fig. 11 (a) Distribution function of phase $a$. (b) Its winding function.

(c) Distribution function of the fictitious coil $f_{1}$.

\section{Appendix C}

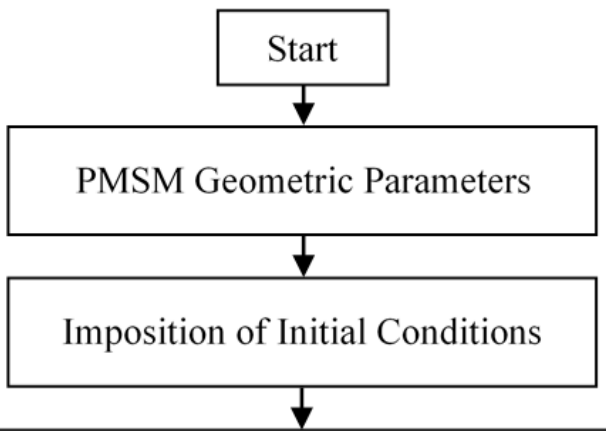

Calculation of the different PMSM parameters such as: $\left[R_{s}\right],\left[M_{s s}\right]$ and $\left[M_{f}\right]$

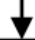

Solving of the PMSM differential equations using the Runge Kutta method

Fig. 12 Flowchart of the developed program
Storage of the obtained Results

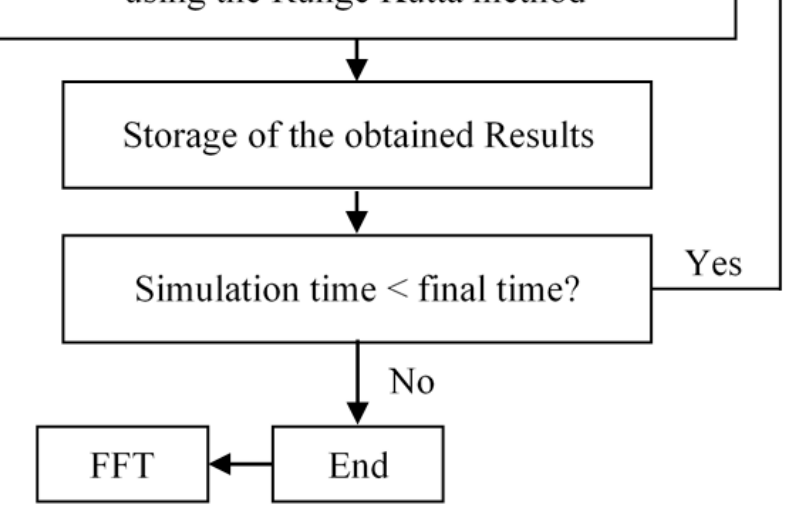

